\title{
Study on Mooring System Design of Floating Offshore Wind Turbine in Jeju Offshore Area
}

\author{
Hyungjun Kim ${ }^{1}$, Gi-Young Jeon ${ }^{1}$, Joonmo Choung ${ }^{1 *}$ and Sung-Won Yoon ${ }^{1}$ \\ ${ }^{l}$ Department of Naval Architecture and Ocean Engineering, Inha University, Korea
}

(Manuscript Received September 27, 2013; Revised November 1, 2013; Accepted November 29, 2013)

\begin{abstract}
This paper presents a mooring design procedure for a floating offshore wind turbine. Offshore environmental data for Jeju are taken from KHOA (Korea Hydrographic and Oceanographic Administration) and used for the environmental conditions in numerical analyses. A semi-submersible-type floating wind system with a 5-MWclass wind turbine studied by the DeepCwind Consortium is applied. Catenary mooring with a studless chain is chosen as the mooring system. Design deliverables such as the nominal sizes of chain and length of the mooring line are decided by considering the long-term prediction of the breaking strength of the mooring lines where a 100 -year return period is used. The designed mooring system is verified using a fatigue calculation based on rainflow cycle counting, an S-N curve, and a Miner's damage summation of rule. The mooring tension process is obtained from time-domain motion analyses using ANSYS/AQWA.
\end{abstract}

Keywords: Floating type platform, Semi-submersible mooring system, Catenary mooring, Fatigue life, Line tension

\section{Introduction}

The depletion of fossil fuels and consequent environmental pollution have been elevating concerns about sustainable green energy sources. There have been many attempts to convert renewable energy sources such as solar, wind, tide, and wave sources into commercialized energy. In particular, interest in offshore wind power, which is known to have a high economic feasibility, is growing. In recent years, much attention has been given to offshore wind power installations because the wind resources are better than those on land, and they can be placed far from shore (deep zone), which means they are free from other complaints like noise pollution.

For these reasons, many studies on floating wind power generators are ongoing internationally and

*Corresponding author. Tel.: +82-32-860-7346, Fax.: +82-32-860-5850,

E-mail address: jmchoung@inha.ac.kr

Copyright $($ ) KSOE 2013. domestically. Shin and Kim (2011) from the NREL (National Renewable Energy Laboratory) contributed to the current study by applying a catenary mooring system to the spar-type wind turbines proposed for the motion analysis. Yu et al. (2013) applied offshore data from the South China Sea to predict the behavior of the mooring system of a spar-type wind turbine, which is known as the OC3-Hywind. Brommundt et al. (2012) used the results of a frequency domain analysis to suggest the ultimate load conditions and normal operating conditions with the optimal arrangement of catenary mooring lines for a semi-submersible wind turbine operated in a particular area of the North Sea. In Norway's Statoil hydro, a successful operation was conducted by applying a catenary mooring system to a spar-type floating wind turbine, based on the experience gained by applying a catenary mooring method offshore. However, among the many studies, little mention is made of a method for designing the mooring line system for 
an offshore wind generator and the specific process. In addition, an analysis of the marine data for a domestic JEJU offshore area, a motion analysis for the environmental conditions, and research on the fatigue strength of mooring lines have not been performed.

In this paper, a floating body motion analysis is performed by applying the marine data for an excellent wind condition in a JEJU offshore area. NREL applied a 5-MW-class semi-submersibletype floating wind system (DeepCwind) to a wind turbine and floating system. Catenary mooring with studless chain is chosen as the mooring system, with the nominal diameter and total length of the mooring lines as the design parameters. The response of the mooring lines is determined by the response of the floating wind system. For the design and safety evaluation of the mooring lines, a fluid dynamics analysis of the floating wind system is necessary. For these reasons, a motion analysis of floating wind system with Ansys/aqwa code is performed through a fully coupled analysis method that includes the current force, wind loads (thrust), wave force, and mooring forces.

A safety evaluation of the mooring system is performed using the ultimate limit state (ULS) and fatigue limit state (FLS). The ultimate limit state for a return period of 100 years is used to predict the maximum tensile strength through a Weibull distribution estimation, and the fatigue limit state based on a design life of 50 years is calculated by using Miner's rule for a linear damage summation.

In this paper, the Ansys/aqwa code is validated through a comparison/analysis with the mooring line's nominal diameter as a design variable. Model tests for the mooring lines system are also designed to determine the total length of the mooring lines through a floating motion analysis and safety evaluation. Because a larger nominal diameter for the mooring lines results in a shorter total length, the most economical diameter is found by comparing the total weight of the mooring lines.

\section{Design Procedure}

The mooring line design process is shown in Fig. 1. First, after determining the basic specifications of the platform, a linear analysis is carried out, along with the verification of the model by considering the given offshore environment. Moreover, the initial design of the mooring lines, considering the type of mooring line and the initial tension, and the safety of mooring lines are examined when the mooring lines are installed. After the safety assessment for the equilibrium position, the tension histories of the mooring lines are calculated through a motion analysis in the time domain. A final verification is carried out by calculating and comparing each piece of data on the structural strength and fatigue strength.

\section{Environmental Condition}

The environmental data of the area were collected to review the domestic offshore wind resources to select possible regions for further development. The average wind speed off the southern coast of JEJU is $8.0-8.5 \mathrm{~m} / \mathrm{s}$. Thus, the wind condition is excellent. When installing wind turbines, the wind condition is expected to be highly utilized. This is why the southern coastal area of JEJU is selected as the wind turbine installation area.

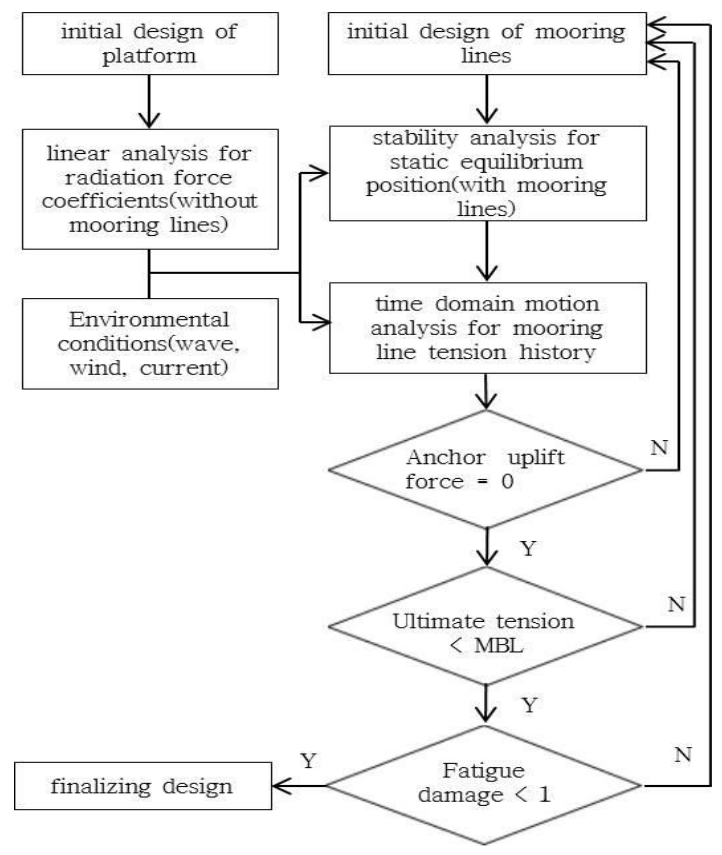

Fig. 1. Design procedure for mooring lines. 


\begin{tabular}{|c|ccccccccc|}
\hline $\mathrm{Tz}(\mathrm{s})$ & 3 & 4 & 5 & 6 & 7 & 8 & 9 & 10 & sum \\
\hline $\mathrm{Hs}$ & & & & & & & & & \\
$(\mathrm{m})$ & & & & & & & & & \\
0.5 & 2421 & 3555 & 993 & 23 & 1 & 0 & 0 & 0 & 6993 \\
1.5 & 0 & 693 & 2853 & 1019 & 83 & 6 & 0 & 0 & 4654 \\
2.5 & 0 & 0 & 96 & 573 & 210 & 26 & 8 & 0 & 913 \\
3.5 & 0 & 0 & 0 & 11 & 51 & 13 & 0 & 0 & 75 \\
4.5 & 0 & 0 & 0 & 0 & 8 & 10 & 3 & 0 & 21 \\
5.5 & 0 & 0 & 0 & 0 & 1 & 5 & 3 & 2 & 11 \\
6.5 & 0 & 0 & 0 & 0 & 5 & 3 & 3 & 0 & 11 \\
7.5 & 0 & 0 & 0 & 0 & 3 & 3 & 4 & 0 & 10 \\
8.5 & 0 & 0 & 0 & 0 & 1 & 0 & 0 & 3 & 4 \\
9.5 & 0 & 0 & 0 & 0 & 0 & 0 & 0 & 4 & 4 \\
sum & 2421 & 4248 & 3942 & 1626 & 363 & 66 & 21 & 9 & 1269 \\
\end{tabular}

Fig. 2. Wave scatter diagram for Jeju offshore area. rent.

\section{2 Wave Scatter Diagram}

In this paper, ocean data for 2011-2012 are used, including data from the IEODO ocean research station, which is equipped with state-of-the-art ocean, meteorology, and environmental observation systems. In order to apply the ocean state, a wave scatter diagram should be created. The significant wave height and zero-upcrossing period are measured every hour, and the data are divided into 80 different sections of short-term offshore conditions. In addition, referring to the IEODO ocean research

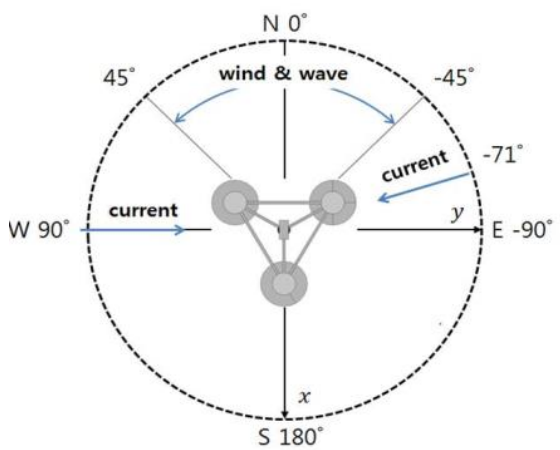

Fig. 3. Directional spreading of wind, waves, and cur-

station data, the area with the fastest current velocity is found, and the current velocity and direction are determined for that area.

\subsection{Load Condition}

The environmental data are collected using the above process. In addition, when north is $0^{\circ}$ based on the area where the current velocity is the fastest, the average current velocities of the flood tide and ebb tide reached $251^{\circ}$ and $90^{\circ}$, respectively.

Table 1 Load cases according to environmental conditions.

\begin{tabular}{|c|c|c|c|c|c|c|}
\hline \multirow{2}{*}{ Condition No. } & \multicolumn{3}{|c|}{ Current } & \multicolumn{2}{|c|}{ Wind \& wave } & \multirow{2}{*}{$\begin{array}{c}\text { Probability } \\
(\%)\end{array}$} \\
\hline & $\begin{array}{l}\text { Dir. } \\
\text { (deg) }\end{array}$ & Speed $(\mathrm{m} / \mathrm{s})$ & $\%$ & $\begin{array}{l}\text { Dir. } \\
\text { (deg) }\end{array}$ & $\%$ & \\
\hline 1 & & & & 45 & 10 & 5 \\
\hline 2 & & & & 22.5 & 20 & 10 \\
\hline 3 & -71 & 1.13 & 50 & 0 & 40 & 20 \\
\hline 4 & & & & -22.5 & 20 & 10 \\
\hline 5 & & & & -45 & 10 & 5 \\
\hline 6 & & & & 45 & 10 & 5 \\
\hline 7 & & & & 22.5 & 20 & 10 \\
\hline 8 & 90 & 1.48 & 50 & 0 & 40 & 20 \\
\hline 9 & & & & -22.5 & 20 & 10 \\
\hline 10 & & & & -45 & 10 & 5 \\
\hline
\end{tabular}


Table 2 Main dimensions and characteristics of platform.

\begin{tabular}{|c|c|}
\hline \multicolumn{2}{|c|}{ Wind turbine system } \\
\hline Rating & $5 \mathrm{MW}$ \\
\hline Rated wind speed (m/s) & 11.4 \\
\hline Nacelle mass (m) & 240000 \\
\hline Blade mass (for each) (m) & 18000 \\
\hline Hub mass (m) & 56000 \\
\hline Tower mass (m) & 249718 \\
\hline \multicolumn{2}{|c|}{ Platform system } \\
\hline Mass (m) & 13473000 \\
\hline Roll inertia $\left(\mathrm{kg} \cdot \mathrm{m}^{2}\right)$ & $6.827 \mathrm{E}+9$ \\
\hline Pitch inertia $\left(\mathrm{kg} \cdot \mathrm{m}^{2}\right)$ & $6.827 \mathrm{E}+9$ \\
\hline Yaw inertia $\left(\mathrm{kg} \cdot \mathrm{m}^{2}\right)$ & $1.23 \mathrm{E}+10$ \\
\hline $\mathrm{KG}(\mathrm{m})$ & 6.54 \\
\hline Draft (m) & 20.2 \\
\hline
\end{tabular}

As previously mentioned, a wave scatter diagram is used to represent a total of 34 short-term sea states with a Pierson-Moskowitz spectrum. According to the year-round wind data for the corresponding area, with the exception of summer, a north wind blows most frequently, and from late autumn to winter, the wind condition is relatively good. Therefore, the probabilities for the incident directions are as follows: $40 \%$ for a north wind, $20 \%$ each for NNW and NNE winds, and $10 \%$ each for NW and NE winds. For a conservative design, the wave and wind directions are applied equally. Thus, a total of 10 load cases with 5 different wind and wave directions and 2 different currents are applied.

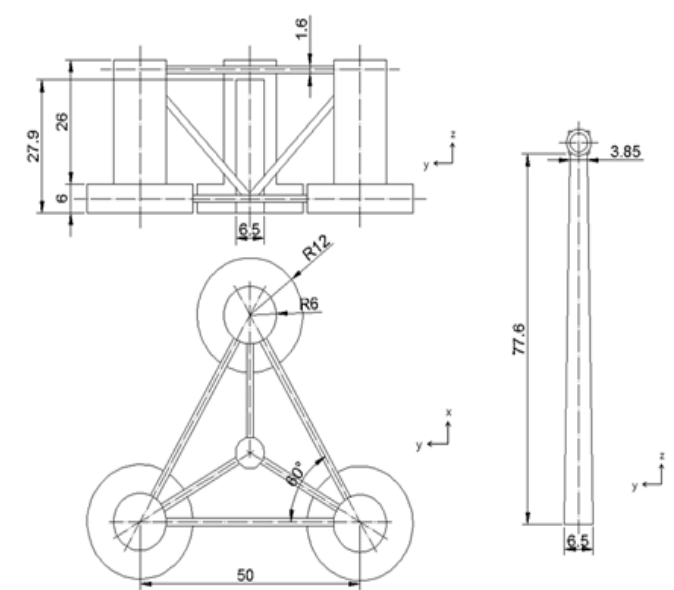

Fig. 4. Dimensions of platform.

\section{Hydrodynamic Analysis Procedure Verifi-} cation

\subsection{Platform Characteristics}

In this paper, a semi-submersible platform consisting of three pillars developed by the DeepCwind consortium is selected, and a 5-MW-class generator proposed by NREL is applied to the wind turbine. Table 2 shows the basic characteristics of the structure, and Fig. 4 presents the dimensions of each part. The characteristics of the 5-MW-class wind turbine are taken from the reference.
$D=$ Nominal Diameter

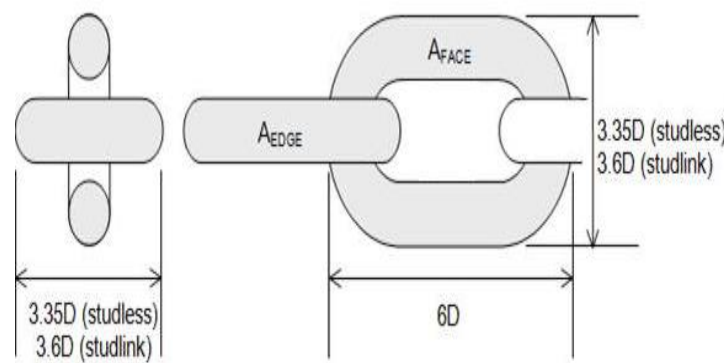

Table 3 Mooring system properties.

\begin{tabular}{l|c}
\multicolumn{2}{c}{ Mooring system } \\
\hline No. of lines & 3 \\
Depth to fairleads below SWL (m) & 14.6 \\
Distance to anchors from platform center $(\mathrm{m})$ & 837.6 \\
Line length $(\mathrm{m})$ & 835.5 \\
Nominal diameter $(\mathrm{m})$ & 0.095 \\
Line mass density $(\mathrm{kg} / \mathrm{m})$ & 113.35 \\
Axial stiffness $(\mathrm{N})$ & $753.6 \mathrm{e} 6$ \\
\hline \hline
\end{tabular}

Fig. 5. Chain geometry. 


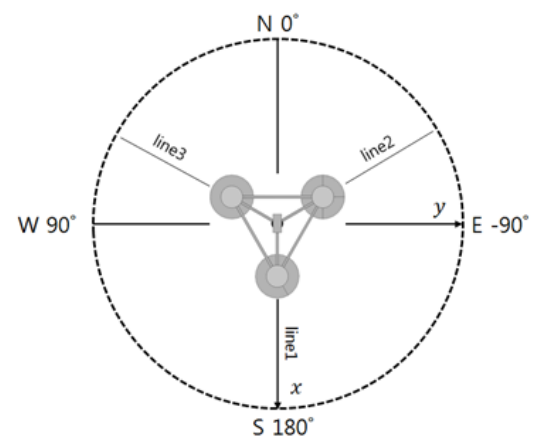

Fig. 6. Mooring configuration.

\subsection{Mooring Line Characteristics}

Catenary mooring with studless chains is chosen as the mooring system, and the detailed specifications are given in Table 3.

Fig. 5 shows the general mooring line chain shape. The DNV rules encourage the use of offshore structure drag coefficients of 2.4 and 1.15 for the longitudinal and transverse directions of a studless chain. The configuration of mooring lines with $120^{\circ}$ intervals is as shown in Fig. 6.

\subsection{Panel Element Modeling}

In this paper, using the Ansys/aqwa code, floating body motion is calculated in the time domain. In order to use the Ansys/aqwa code, based on the still water level, the area below the surface should be composed of diffraction or Morison elements. According to the above information, the modeling is performed using Altair/HyperMesh with 4547 kinds of diffraction elements and 15 kinds of tube elements. The maximum size of a diffraction

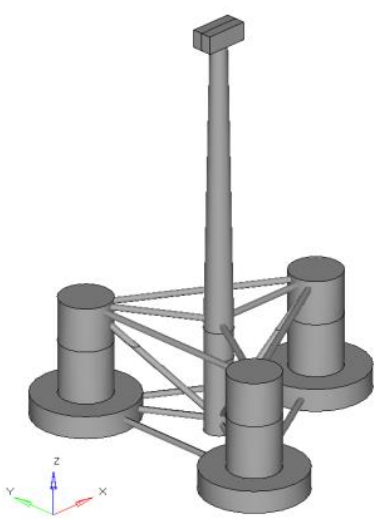

element is $1.4 \mathrm{~m}$, and an analysis of an incident wave with a wavelength of at least $9.8 \mathrm{~m}$ is possible. Assuming a deep sea, it is possible to perform an analysis of incident waves with a minimum cycle of $2.5 \mathrm{~s}$ or a maximum of $2.5 \mathrm{rad} / \mathrm{s}$. In this paper, only the quasi-static drag force, which occurs in the blades of a wind turbine, is considered, and the aerodynamic load is not considered. Because we calculated the motion of a floating body, modeling is conducted without wind turbine wings. Each mass and mass of inertia moment is designated at the centers of mass of the nacelle, tower, and platform. The left image of Fig. 7 shows the shape of the platform, wind turbine tower, and nacelle. The right image of Fig. 7 shows the necessary diffraction and tube elements (Morison elements) for the Ansys/aqwa analysis.

\subsection{Motion Response Comparison}

In this paper, the RAO (Response Amplitude Operator) that was calculated by using the Ansys/aqwa code and applying the modified damping constant is compared with the RAOs of the model test results and simulation using the UOU-FAST code conducted by Shin (2013).

Fig. 8 compares the results of the RAOs for the surge, heave, and pitch found in Shin (2013). Fig. 8 does not show the remaining degrees of freedom because the size of the RAOs is very small.

According to the comparison results in Fig. 8, the numerical analysis results of UOU-FAST and the Ansys/aqwa code generally show a greater response than the UOU-model test results. However, because the difference is very small, the Aqwa code is proven to be suitable for use.

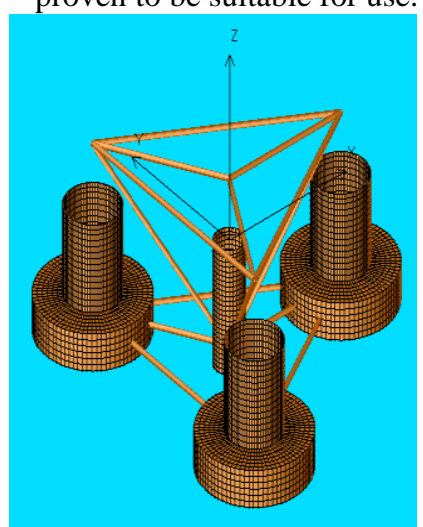

Fig. 7. Illustration of platform, tower, nacelle, and diffraction elements. 

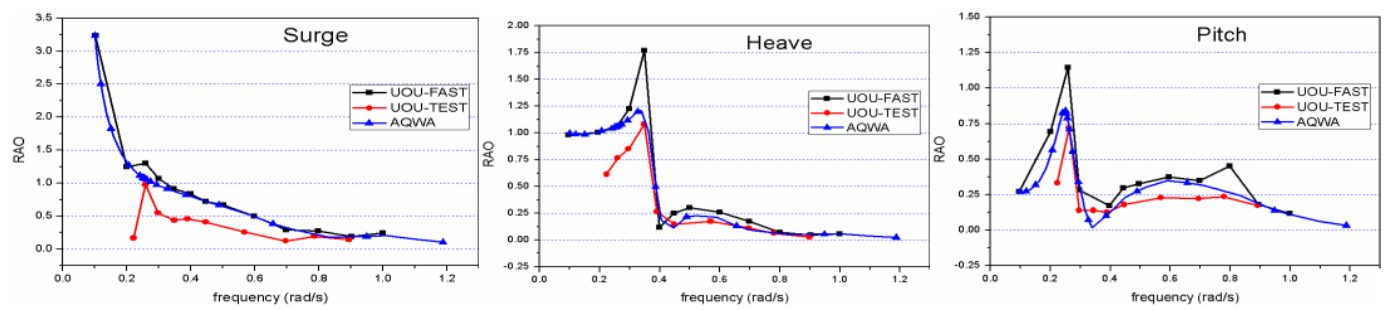

Fig. 8. Motion RAOs comparing results of UOU test, FAST simulation, and AQWA/FER analysis.

\section{Hydrodynamic Analysis}

\subsection{Mooring Line Type and Length Decision}

In this paper, the water depth is set to $120 \mathrm{~m}$, and three nominal chain diameters are considered: 85 $\mathrm{mm}, 95 \mathrm{~mm}$, and $105 \mathrm{~mm}$. To determine the initial length, a catenary equation is applied, and the proof load of chain grade R3 is chosen to determine the maximum tension based on the DNV rules. In the following figure, the distance between the first contact point for the mooring line and seabed, and the anchoring points, is called the safety length or laid length of mooring lines. The total length of the mooring line is only determined after this safety length is determined. In the DNV rules, the safety length must be long enough to prevent the anchor uplift force with the seabed at the anchoring point (DNV-OS-E301). Thus, the total length is adjusted to avoid the normal force at the anchoring point from the initial length when applying the environmental load.

\subsection{Static Analysis}

In the static analysis phase, only the current and wind loads are considered when finding the equilibrium position of the floating system. The equilibrium position is calculated from the static load and restoring force of the mooring lines. First, the minimum length of the mooring lines is determined using the catenary equation, and the static position is found by increasing the total length. In the static equilibrium position, a minimum safety length of $200 \mathrm{~m}$ is applied. The following table lists the safety lengths of the most severe 5 and 6 load conditions, when the nominal diameter is $95 \mathrm{~mm}$. The length of each line refers to the increase in the total length of the mooring lines causing the minimum safety length to reach a value greater than $200 \mathrm{~m}$

\subsection{Time Domain Analysis}

By applying a wave scatter diagram, a timedomain analysis is performed for 10 kinds of load conditions. In the wave scatter diagram, a total of 34 short term sea states exist. Thus, a total of 340 analyses are conducted with 10 kinds of load conditions. In the time domain analysis, calculations are carried out using the Aqwa/drift module, to consider the quadratic term of the wave velocity potential, which represents the wave drift force. The simulation of any external force causing the floating body motion is performed for $1 \mathrm{~h}$. After this, when the normal force occurs at the anchoring point, a re-analysis is performed by changing the total length of the mooring lines. Through an iterative process, the total length of the final mooring lines is determined.

Table 4 Modified safety length of condition 5 and condition 6 .

\begin{tabular}{c|c|l|l}
\hline \hline \multicolumn{2}{c|}{$\begin{array}{c}\text { Condition 5 } \\
\text { Safety length }\end{array}$} & \multicolumn{2}{c}{$\begin{array}{c}\text { Condition 6 } \\
\text { Safety length }\end{array}$} \\
\hline Line 1 & $262.28 \mathrm{~m}$ & Line 1 & $200.93 \mathrm{~m}$ \\
Line 2 & $203.93 \mathrm{~m}$ & Line 2 & $492.49 \mathrm{~m}$ \\
Line 3 & $490.19 \mathrm{~m}$ & Line 3 & $202.01 \mathrm{~m}$ \\
\hline \hline
\end{tabular}

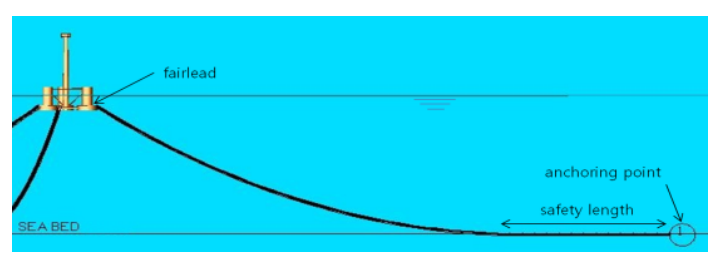

Fig. 9. Safety length in catenary mooring. 


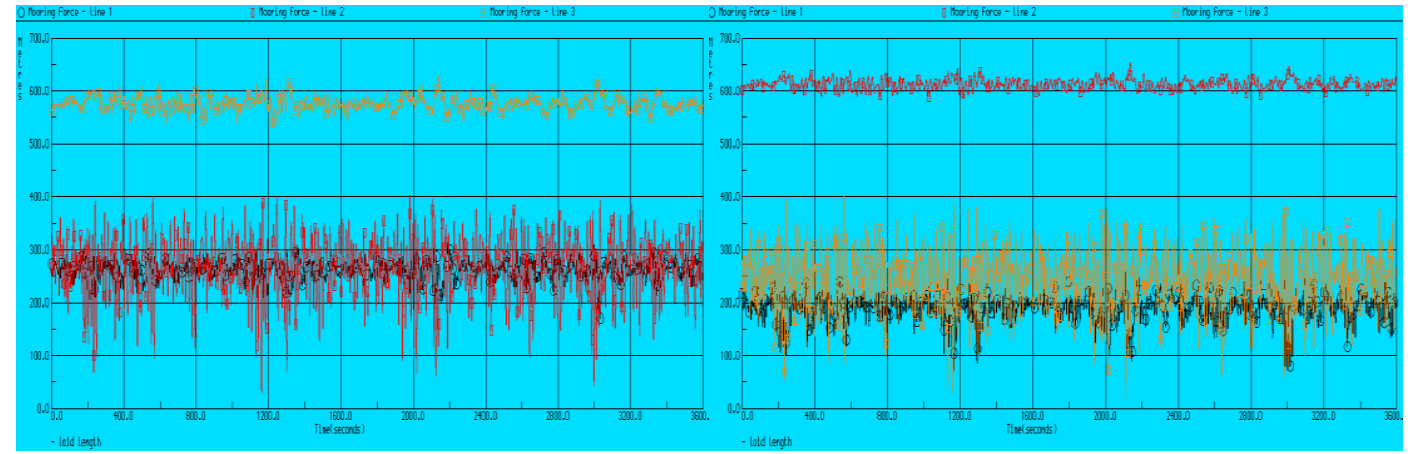

Fig. 10. Time domain analysis of condition 5 and condition 6 .

As the following figure shows, there is no normal force at the anchoring point because the safety length of all the lines appears to be greater than $0 \mathrm{~m}$ when the time domain is analyzed using the total length of the final mooring lines. Moreover, the time history of the mooring tension is drawn by applying the time domain analysis results for the final mooring configuration design.

\section{Structural Strength and Fatigue Strength}

\section{Analysis}

\subsection{Ultimate Limit State}

In this paper, to determine the ultimate limit state, a simulation is conducted for $1 \mathrm{~h}$. An effective range for the mooring line tension is determined from the tension history using rainflow cycle counting.

After the range counting, the tension ranges are extended for the long-term wave state from the probability of the wave scatter diagram. The maximum tension for a 100 -year return period is calculated using the Weibull distribution and linear regression model. In addition, the maximum tension for the 100-year return period is calculated from the mooring line's tension data corresponding to 2

Table 5 Maximum tension range for return period of 100 years.

\begin{tabular}{c|c}
\hline \hline & Tension range $(\mathrm{kN})$ \\
\hline line1 & 4596.20 \\
line2 & 9265.43 \\
line3 & 8991.13 \\
\hline \hline
\end{tabular}

years. The Weibull distribution equation is as follows.

$$
f(R)=\frac{\beta}{q}\left(\frac{R}{q}\right)^{2}
$$

$$
\begin{array}{lll}
R & : & \text { Tension range } \\
\beta & : & \text { Shape parameter } \\
q & : & \text { Scale parameter }
\end{array}
$$

The following table was obtained from the above equation. The maximum tension of each mooring line is summarized.

Regarding the nominal diameter of the three kinds of mooring lines, the total weights and 100-year return-period maximum tensions of the mooring lines are compared and examined. As a result, it is found that an increase in the nominal diameter of the mooring lines causes a decrease in the total length, whereas an increase in the total mass causes an increase in the maximum tension, according to the graph.

Table 6 Accumulative damage for 50 years

\begin{tabular}{c|c}
\hline \hline & Damage \\
\hline line1 & 0.0874 \\
line2 & 0.2450 \\
line3 & 0.3782 \\
\hline \hline
\end{tabular}




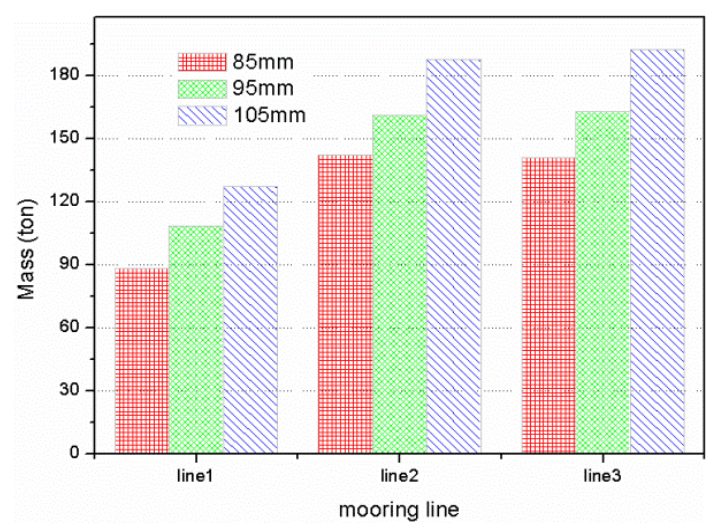

Fig. 11. Total mass of mooring lines.

In contrast, a decrease in the nominal diameter of the mooring lines causes an increase in the total length, and decreases in the total mass and maximum tension. When compared with MBL (Minimum Breaking Load) as recommended in DNV, in terms of the ultimate limit state, applying chain grade R5 is found to be the most economical model, with a nominal chain diameter of only 85 $\mathrm{mm}$. Moreover, chain grade $\mathrm{R} 4 \mathrm{~S}$, which has a nominal diameter that is larger than $95 \mathrm{~mm}$, shall be used.

\subsection{Fatigue Limit State}

By using the tension range data, linear damage accumulation rule, and $\mathrm{S}-\mathrm{N}$ curve, the cumulative fatigue damage is determined. Assuming 50 years for the design life, the accumulated damage is calculated for each mooring line over 50 years.

$$
\begin{aligned}
& \text { D } \\
& =\sum_{i=1}^{k} \frac{n_{i}}{N_{i}} \quad N_{i}=\frac{a_{D}}{S_{i}^{m}} \\
& n_{i} \quad: \quad \text { Iteration number of stress range }\left(S_{i}\right) \\
& N_{i} \quad: \quad i \text {-th fatigue life of tension range } \\
& a_{D}, m: \begin{array}{l}
\text { S-N curve parameters } \\
\left(a_{D}=6.0 \times 10^{10}, m=3.0\right)
\end{array}
\end{aligned}
$$

Thus, the cumulative damage is calculated for 50 years for the three mooring lines and summarized in the table.

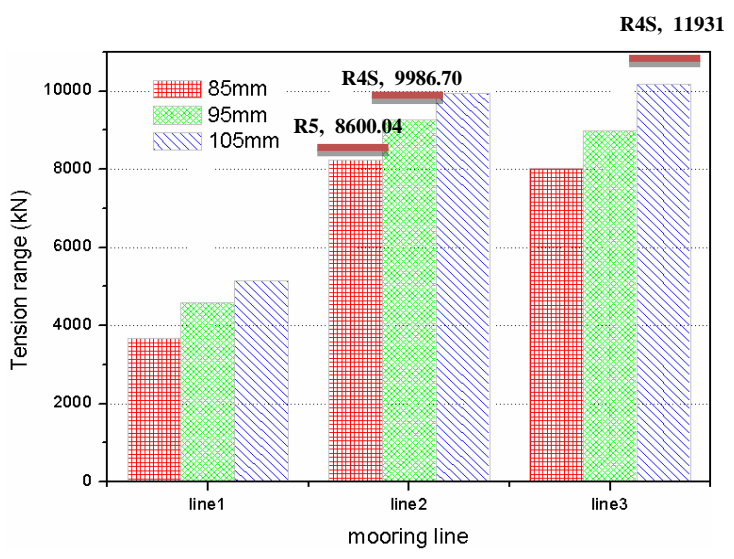

Fig. 12. 100-year return period maximum tension range.

The following graph shows that an increase in the nominal diameter produces a decrease in the amount of damage for the fatigue limit state. Considering the fatigue limit state, the nominal chain diameters for the three kinds of lines satisfy the design criteria. Thus, from the point of view of the ultimate limit state, the nominal chain diameter and grade decisions can be recommended.

\section{Conclusion}

In this paper, wind and offshore data were collected from the IEODO ocean research station, located in the south coast region of Jeju Island, which has superior wind conditions. In addition, the OC4 offshore wind turbine platform was used as a model and the adequacy of the hydrodynamics analysis was verified in comparison with the results of the UOU model experiments and FAST code.

A catenary mooring type consisting of a studless chain was adopted, and the nominal diameter and total length of the mooring lines were set as the

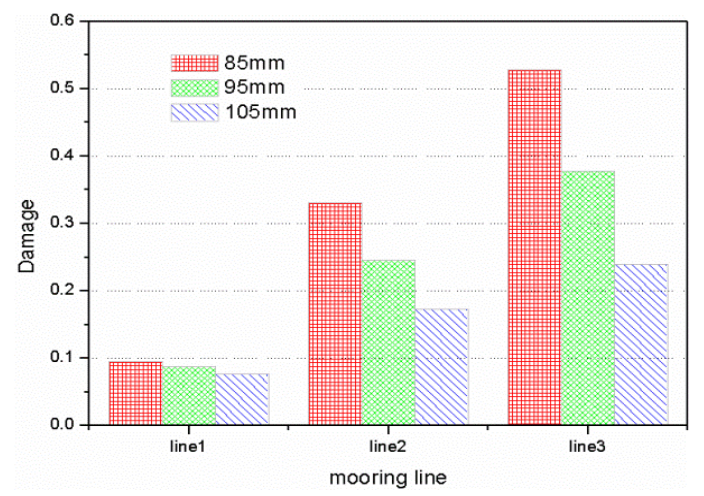

Fig. 13. Cumulative damage for 50 year. 
design parameters. Thus, by applying the catenary equation to determine the initial length of the mooring lines and examining the occurrence of the normal force at the anchoring point through an analysis of the static equilibrium position, the static minimum safety length of the mooring lines was determined. Through a time-domain hydrodynamic analysis, the minimum safety length of the mooring lines was determined, and based on the final configuration design, the mooring line tension time history was drawn. In the ultimate limit state analysis, the maximum tension range for a 100-year return period was predicted using a Weibull distribution prediction, and the results were compared with the minimum breaking load of the mooring lines. In the fatigue limit state analysis, 50 years worth of cumulative fatigue damage was determined by using the tension range data, linear cumulative damage rule, and S-N curve. Thus, the mooring lines of a floating offshore wind turbine and design procedures suitable for the Jeju offshore area were established.

In this study, all the procedures from collecting the ocean data to the necessary safety estimation were carried out. Based on this study, how an aerodynamic load impacts a platform's hydrodynamic behavior will be examined. In addition, a study to examine the OPB (Out of Plane Bending) fatigue of a chain will be carried out.

\section{Acknowledgment}

This work was supported by a Special Education Program for Offshore Plant by the Ministry of Trade, Industry and Energy Affairs (MOTIE). This work was also supported by a Manpower Development Program for Marine Energy by the Ministry of Land, Transport and Maritime Affairs (MLTM). The authors are grateful to INHA University for funding research grant.

\section{References}

[1] Ansys (2010a). AQWA User's Manual Version 13.0, USA.

[2] Ansys (2010b). AQWA Reference Manual Version 13.0, USA.

[3] ASTM, 2005. Standard Practice for Cycle Counting in Fatigue Analysis. E 104985(Reapproved 2005), ASTM International, USA.
[4] Brommundt, M., Krause, L., Merz, K., Muskulus, M., (2012). Mooring system optimization for floating wind turbines using frequency domain analysis, Energy Procedia 24 ; 289-296.

[5] Det Norske Veritas(DNV) (2010a). Offshore Standard DNV_OS_E301, Position Mooring. DNV, Norway.

[6] Det Norske Veritas (DNV) (2010b). Recommended Practice DNV_RP_C205, Environmental Conditions and Environmental Loads. DNV, Norway.

[7] Frank M. White (2008). Fluid Mechanics, $6^{\text {th }}$ Edition, McGraw-Hill, New York.

[8] Jung, D.H., Nam, B.W., Shin, S.H., Kim, H.J., Lee, H.S., Moon, D.S., Song, J.H., (2012). Investigation of Safety and Design of Mooring Lines for Floating Wave Energy Conversion, Journal of Ocean Engineering and Technology Vol. 26-4: 77-85.

[9] J. Jonkman, S. Butterfield, W. Musial and G. Scott (2009). Definition of a 5-MW Reference Wind Turbine for Offshore System Development, NREL/TP-500-38060, Renewable Energy Laboratory, Colorado, USA.

[10]Maruo, H., 1960. The Drift of a Body Floating in Waves. Journal of Ship Research, 4(3), USA.

[11]Shin, H.K., Kim, K.M., (2011). Motion Analysis of 5-MW Floating Offshore Wind Turbine, Journal of Ocean Engineering and Technology, 25(5): 64-68.

[12]Shin, H.K., (2011). Model Test of the OC3Hywind Floating Offshore Wind Turbine, International Offshore and Polar Engineering Conference, Maui, Hawaii, USA.

[13]Shin, H.K., (2013). OC4 Semi-Submersible Offshore wind turbine model test \& simulation by UOU-FAST, Annual spring meeting, KAOSTS-SNAK, Jeju.

[14]Xiaohong C., Jun Z., Wei M., (2001). On dynamic coupling effects between a spar and its mooring lines, Ocean Engineering, Vol. 28: 863-887.

[15]Yu M., Zhiqiang H., (2013). Dynamic analysis for a spar-type wind turbine under different sea states, International Conference on Ocean, Offshore and Arctic Engineering, Nantes, France. 